\title{
SIMULTANEOUS DETERMINATION OF MASS AND VOLUME OF A SET OF WEIGHTS IN GROUP WEIGHING
}

\author{
Ch. Wuethrich ${ }^{1}$, K. Marti ${ }^{2}$ \\ ${ }^{1}$ Federal Institute of Metrology METAS, Switzerland, christian.wuethrich@ metas.ch \\ ${ }^{2}$ Federal Institute of Metrology METAS, Switzerland, kilian.marti@metas.ch
}

\begin{abstract}
:
This work introduces a new technique for the determination of mass and volume of a set of weights based on closed series (group weighing). A traditional closed series is repeated at two different air densities. A least squares set of equations, involving two Lagrange multipliers, is used to determine the mass and the volume of each weight simultaneously with a traceability on the mass and the volume of the reference weight.
\end{abstract}

Keywords: double weighing; closed series; group weighing; volume determination

\section{INTRODUCTION}

The determination of mass in air is always strongly affected by air buoyancy. Traditionally, the volume of weights is determined by hydrostatic weighing and used for the correction of air buoyancy. Recently, several authors used double weighing in air of different density in order to determine the mass and the volume of an unknown artefact $[1,2]$. The determination of the sub-multiples and the multiples of the kilogram still requires, in order to have an independent definition of the mass at NMI level, the volume determination through hydrostatic weighing [3]. We propose a technique of closed series in which the volume is an unknown of the system and is determined simultaneously with the mass by a set of double weighings in air of different densities.

\section{THEORETICAL FOUNDATIONS}

\subsection{Traditional closed series}

A closed series is traditionally defined by a weighing scheme (design matrix) $\boldsymbol{X}$ which is given as a combination of $0,-1$ or +1 depending on whether or not the weight is involved in the comparison and whether the weight is considered to be a positive or a negative contribution to the weighing equation. The matrix $\boldsymbol{X}$ has $p$ columns, corresponding to the number of weights involved in the process and $n$ rows, representing the number of weighing operations. It is possible to determine the mass values of the weights if $p=n$ but it is better, in order to verify the consistency of the measurements, to have redundancy with $n>p$. This way, the determination of the mass values is realized by calculating the least squares of the overdetermined system of equation by applying the Lagrange multiplier method described by Kochsiek et al. [4]. This technique is widely spread in the determination of the conventional value of the mass.

\subsection{Closed series with known volumes and air buoyancy correction}

In order to determine the true mass, the matrix $\boldsymbol{X}$ is converted to $\widehat{\boldsymbol{X}}$ which incorporates a correction for the air buoyancy of each weight at each air density. We define the elements of $\widehat{\boldsymbol{X}}$ in the following way:

$\hat{x}_{i, j}=x_{i, j}\left(1-\frac{\rho_{i}}{D_{j}}\right)$

where $\rho_{i}$ is the air density during weighing $i$ and $D_{j}$ is the material density of weight $j$ [5].

\subsection{Closed series with unknown masses and unknown volumes}

In our innovative technique, the volumes of the weights are considered as unknowns of the system. We write the equation incorporating the buoyancy correction given by the unknown volumes. We repeat the weighing scheme $\boldsymbol{X}$ and use it at two different nominal air densities. Each individual air density is defined by its value $\rho_{1}$ to $\rho_{2 n}$. We define the new matrix $\boldsymbol{Z}$ with $2 p$ columns and $2 n$ rows.

In matrix form we can write

$$
\left(\begin{array}{ccc}
z_{1,1} & \cdots & z_{1, p} \\
\vdots & \ddots & \vdots \\
z_{n, 1} & \cdots & z_{n, p}
\end{array}\right)=\left(\begin{array}{ccc}
z_{n+1,1} & \cdots & z_{n+1, p} \\
\vdots & \ddots & \vdots \\
z_{2 n, 1} & \cdots & z_{2 n, p}
\end{array}\right)=X
$$

and

$$
\begin{aligned}
& \left(\begin{array}{ccc}
z_{1, p+1} & \cdots & z_{1,2 p} \\
\vdots & \ddots & \vdots \\
z_{2 n, p+1} & \cdots & z_{2 n, 2 p}
\end{array}\right)=\cdots \\
& \cdots=-\left(\begin{array}{ccc}
\rho_{1} & \cdots & 0 \\
\vdots & \ddots & \vdots \\
0 & \cdots & \rho_{2 n}
\end{array}\right)\left(\begin{array}{ccc}
z_{1,1} & \cdots & z_{1, p} \\
\vdots & \ddots & \vdots \\
z_{2 n, 1} & \cdots & z_{2 n, p}
\end{array}\right)
\end{aligned}
$$


The unknown values of mass $m_{i}$ and volume $v_{i}$ of the weight $i$ are expressed as

$$
\vec{\gamma}:=\left(m_{1} \ldots m_{\mathrm{p}} v_{1} \ldots v_{\mathrm{p}}\right)^{T}
$$

where $m_{l}$ and $v_{l}$ are the mass and volume of the reference weight. The weighing process is given by

$$
Z \cdot \vec{\gamma}=\vec{y}+\vec{e}
$$

where $\vec{y}=\left(y_{1} \ldots y_{2 n}\right)^{T}$ is the weighing differences in the individual comparisons and $\vec{e}=\left(e_{1} \ldots e_{2 n}\right)^{T}$ is the error associated with the weighing. The normal equation is given by

$$
Z^{T} Z \cdot \vec{\gamma}=Z^{T} \vec{y}+Z^{T} \vec{e}
$$

To solve this redundant system of equations, we apply the Lagrange multiplier method with two supplementary equations based on the multipliers $\lambda_{1}$ and $\lambda_{2}$ to fix both the mass and the volume of the reference weight. We add two columns and two rows of zeros and ones to $\boldsymbol{Z}^{T} \boldsymbol{Z}$ and $\boldsymbol{Z}^{T}$. The matrices and vectors become

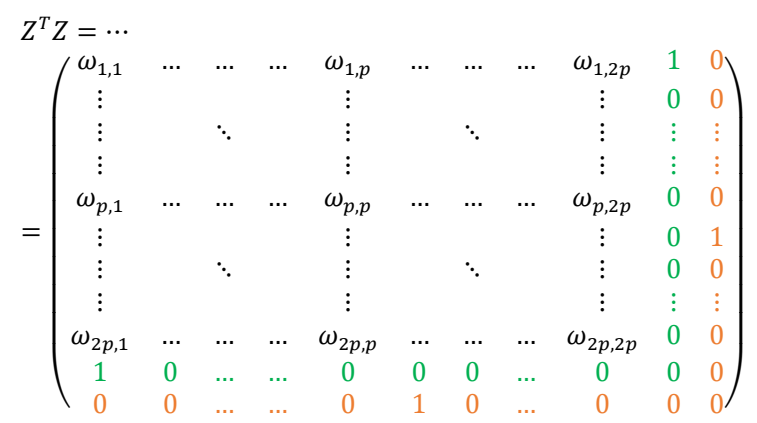

$$
Z^{T}=\left(\begin{array}{ccccccc}
\varphi_{1,1} & \ldots & \varphi_{1, n} & \ldots & \varphi_{1,2 n} & 0 & 0 \\
\vdots & \ddots & \vdots & \ddots & \vdots & \vdots & \vdots \\
\varphi_{p, 1} & \ldots & \varphi_{p, n} & \ldots & \varphi_{p, 2 n} & 0 & 0 \\
\vdots & \ddots & \vdots & \ddots & \vdots & \vdots & \vdots \\
\varphi_{2 p, 1} & \ldots & \varphi_{2 p, n} & \ldots & \varphi_{2 p, 2 n} & 0 & 0 \\
0 & \ldots & 0 & \ldots & 0 & 1 & 0 \\
0 & \ldots & 0 & \ldots & 0 & 0 & 1
\end{array}\right)
$$

$\vec{\gamma}=\left(m_{1} \ldots m_{\mathrm{p}} v_{1} \ldots v_{\mathrm{p}} \lambda_{1} \lambda_{2}\right)^{T}$

$\vec{y}=\left(y_{1} \ldots y_{2 n} m_{r} v_{r}\right)^{T}$

The solution matrix is given by

$L_{S}:=\left(Z^{T} Z\right)^{-1} Z^{T}$.

Finally, the estimated values for the mass and the volume are

$$
\langle\vec{\gamma}\rangle=L_{S} \vec{y} .
$$

\subsection{Monte Carlo Simulation}

We used a Monte Carlo simulation to estimate the measurement uncertainties of the mass and the volume of the weights. For this reason, we vary the input quantities which are the measured weighing difference from the balance, the air density, and the mass and the volume of the reference weight. Furthermore, we assumed the input quantities to be normally distributed

$X \sim \mathcal{N}\left(\mu, \sigma^{2}\right)$.

For the mean value, $\mu$, and the standard deviation, $\sigma$, we use the average value, $\bar{x}$, and the standard deviation, $s$, from the measurements. We assume no correlation between mass and volume of the $1 \mathrm{~kg}$ reference mass. After each variation, we re-calculate the mass and volume of the weights according to Eq. (12). Each re-calculation can be regarded as a random experiment, which is either real or, as in this case, numerically performed by a computer simulation. The number of re-calculations (iterations) is usually $N=10000$. The values for the mass and the volume of the weights as well as their standard uncertainties are given by the mean and standard deviation of the simulated values

$\bar{\gamma}_{j}=\frac{1}{N_{\text {Iter }}} \sum_{p=1}^{N_{\text {iter }}} \gamma_{j, p}$

$s_{\gamma_{j}}=\sqrt{\frac{1}{N_{\text {Iter }}-1} \sum_{p=1}^{N_{\text {iter }}}\left(\gamma_{j, p}-\bar{\gamma}_{j}\right)}$

where $j$ represents the weight and $p$ is the index of the iteration.

\section{MEASUREMENT PROCEDURE}

We determined the mass and the volume of a set of OIML weights from $10 \mathrm{~g}$ to $5 \mathrm{~kg}$ through double weighing measurements in three different mass comparators (see section 4). The first double weighing was carried out at about $950 \mathrm{hPa}$ $\left(\rho_{\text {air }}=1.13 \mathrm{~kg} / \mathrm{m}^{3}\right)$, the second at about $750 \mathrm{hPa}$ $\left(\rho_{\text {air }}=0.90 \mathrm{~kg} / \mathrm{m}^{3}\right)$. The volumes of the weights were additionally measured by hydrostatic weighing in our volume comparators (see section 4). The weighing schemes to cover the selected range of weights are as follows.

$$
\left(\begin{array}{cccccccccc}
-1 & 0 & 0 & 0 & 0 & 1 & 0 & 0 & 0 & 0 \\
-1 & 1 & 0 & 0 & 0 & 0 & 1 & 0 & 0 & 0 \\
0 & -1 & 0 & 0 & 0 & 0 & 1 & 0 & 0 & 0 \\
0 & -1 & 0 & 1 & 1 & 0 & 0 & 0 & 1 & 0 \\
0 & -1 & 1 & 0 & 0 & 0 & 0 & 1 & 0 & 1 \\
0 & 0 & 0 & -1 & 0 & 0 & 0 & 0 & 1 & 0 \\
0 & 0 & 0 & -1 & 0 & 0 & 0 & 1 & 0 & 0 \\
0 & 0 & -1 & 0 & 0 & 0 & 0 & 1 & 0 & 0 \\
0 & 0 & 0 & -1 & 1 & 0 & 0 & 0 & 0 & 1 \\
0 & 0 & -1 & 0 & 1 & 0 & 0 & 0 & 0 & 1 \\
0 & 0 & 0 & 0 & -1 & 0 & 0 & 0 & 0 & 1
\end{array}\right)\left(\begin{array}{c}
m_{100 g} \\
m_{50 g} \\
m_{20^{*} g} \\
m_{20 g} \\
m_{10 g} \\
m_{100 g}^{\prime} \\
m_{50 g}^{\prime} \\
m_{20^{*} g}^{\prime} \\
m_{20 g}^{\prime} \\
m_{10 g}^{\prime}
\end{array}\right)
$$




$\left(\begin{array}{ccccccccc}-1 & 1 & 0 & 0 & 0 & 1 & 0 & 0 & 0 \\ 0 & -1 & 0 & 0 & 0 & 1 & 0 & 0 & 0 \\ 0 & -1 & 0 & 1 & 1 & 0 & 0 & 1 & 0 \\ 0 & -1 & 1 & 0 & 0 & 0 & 1 & 0 & 1 \\ 0 & 0 & 0 & -1 & 0 & 0 & 0 & 1 & 0 \\ 0 & 0 & 0 & -1 & 0 & 0 & 1 & 0 & 0 \\ 0 & 0 & 1 & -1 & 0 & 0 & 0 & 0 & 0 \\ 0 & 0 & 0 & -1 & 1 & 0 & 0 & 0 & 1 \\ 0 & 0 & 0 & 0 & -1 & 0 & 0 & 0 & 1\end{array}\right)\left(\begin{array}{c}m_{1 k \mathrm{~g}} \\ m_{500 \mathrm{~g}} \\ m_{200^{*} \mathrm{~g}} \\ m_{200 \mathrm{~g}} \\ m_{100 \mathrm{~g}} \\ m_{500 \mathrm{~g}}^{\prime} \\ m_{200^{*} \mathrm{~g}}^{\prime} \\ m_{200 \mathrm{~g}}^{\prime} \\ m_{100 \mathrm{~g}}^{\prime}\end{array}\right)$

$$
\left(\begin{array}{cccccccccc}
0 & 0 & 0 & 0 & -1 & 0 & 0 & 0 & 0 & 1 \\
1 & 1 & 1 & 0 & -1 & 0 & 0 & 0 & 1 & 0 \\
0 & 0 & 0 & -1 & 0 & 0 & 0 & 0 & 1 & 0 \\
1 & 0 & 1 & -1 & 0 & 0 & 0 & 1 & 0 & 0 \\
0 & 1 & 0 & -1 & 0 & 1 & 1 & 0 & 0 & 0 \\
0 & 0 & -1 & 0 & 0 & 0 & 0 & 1 & 0 & 0 \\
0 & 0 & -1 & 0 & 0 & 0 & 1 & 0 & 0 & 0 \\
0 & 1 & -1 & 0 & 0 & 0 & 0 & 0 & 0 & 0 \\
1 & 0 & -1 & 0 & 0 & 1 & 0 & 0 & 0 & 0 \\
-1 & 0 & 0 & 0 & 0 & 1 & 0 & 0 & 0 & 0
\end{array}\right)\left(\begin{array}{c}
m_{1 \mathrm{~kg}} \\
m_{2^{*} \mathrm{~kg}} \\
m_{2 \mathrm{~kg}} \\
m_{5 \mathrm{~kg}} \\
m_{10 \mathrm{~kg}} \\
m_{1 \mathrm{~kg}}^{\prime} \\
m_{2^{*} \mathrm{~kg}}^{\prime} \\
m_{2 \mathrm{~kg}}^{\prime} \\
m_{5 \mathrm{~kg}}^{\prime} \\
m_{10 \mathrm{~kg}}^{\prime}
\end{array}\right)
$$

Auxiliary weights are denoted by $m^{\prime}$. They are necessary to stack individual weights on each other so that their sum corresponds to the nominal mass of the reference weight.

\section{INSTRUMENT SETUP}

We describe the technical specifications of our instruments for the double weighing measurements and the hydrostatic measurements.

\subsection{Mass comparators with constant air density}

To perform the double weighing measurements in different air densities, we used different mass comparators from Mettler Toledo: an AT106, a Mone, and an AT10005 (Table 1). All comparators are enclosed in an air-tight chamber in which the air density can be changed by varying the air pressure (Figure 1).

Table 1: Mass comparators with constant air density in the mass laboratory in METAS. Readability, repeatability, maximum load and weighing range of each comparator are shown

\begin{tabular}{|l|c|c|c|}
\hline & AT106 & Mone & AT10005 \\
\hline Read. & $1.0 \mu \mathrm{g}$ & $0.1 \mu \mathrm{g}$ & $10 \mu \mathrm{g}$ \\
\hline Repeat. & $1.5 \mu \mathrm{g}$ & $0.5 \mu \mathrm{g}$ & $20 \mu \mathrm{g}$ \\
\hline Max load & $111 \mathrm{~g}$ & $1001.5 \mathrm{~g}$ & $10011 \mathrm{~g}$ \\
\hline Range & $5 \mathrm{~g}-100 \mathrm{~g}$ & $100 \mathrm{~g}-1 \mathrm{~kg}$ & $1 \mathrm{~kg}-10 \mathrm{~kg}$ \\
\hline
\end{tabular}

To change the air pressure we use a membrane pump (813.3, KNF Neuberger). The pressure, temperature and humidity of the air inside the chamber are recorded during the measurements. The pressure is measured by a Druck DPI 141 Precision Pressure Indicator with a range of $(800-1150) \mathrm{hPa}$ and a resolution of $0.01 \mathrm{hPa}$; and a Fluke RPM4 with a range of $(0-280) \mathrm{MPa}$ and a resolution of $1 \mathrm{ppm}$. The temperature is determined with an accuracy of $0.01^{\circ} \mathrm{C}$ by means of $10 \mathrm{k} \Omega$ normal resistors (Fluke), precision thermistors (YSI Inc.), and a digital multimeter (Keithley 2010). The humidity is measured by a hygrometer (Hygrolab 2, Rotronic AG) with a resolution of $1 \% \mathrm{RH}$ between $(40-60) \% \mathrm{RH}$.

\subsection{Volume comparators}

For the hydrostatic weighing, we used two different comparators from Mettler-Toledo: an AT1005 for the volume comparator VK1, and a PR10003 for the volume comparator VK10 (Table 2). The suspension is connected to the comparator and carries both the test weight and the reference weight (VK1) or the test weight only (VK10). The suspension is immersed in pure water (ELGA Labwater, PURELAB). By means of the well-known water density, the volume of the test weight is determined. Details can be found elsewhere [6].

Table 2: Volume comparators for hydrostatic weighing in the mass laboratory in METAS

\begin{tabular}{|l|c|c|}
\hline & AT1005 & PR10003 \\
\hline Read. & $10 \mu \mathrm{g}$ & $1 \mathrm{mg}$ \\
\hline Repeat. & $20 \mu \mathrm{g}$ & $2 \mathrm{mg}$ \\
\hline Max load & $1009 \mathrm{~g}$ & $10100 \mathrm{~g}$ \\
\hline Range & $\leq 1 \mathrm{~kg}$ & $\leq 10 \mathrm{~kg}$ \\
\hline
\end{tabular}

\section{VALIDATION WITH A SET OF WEIGHTS}

We measured a set of OIML weights ranging from $10 \mathrm{~g}$ to $5 \mathrm{~kg}$ in double weighing measurements according to the weighing schemes in section 3 . We calculated the masses and the volumes according to the methods presented in sections 2.3 and 2.4.

The volumes of the weights obtained from the double weighing measurements and from the hydrostatic measurements are summarised in Table 3 with the expanded measurement uncertainties in brackets. We observed that the measurement uncertainty of the volume depends on the nominal mass of the weight. Below $1 \mathrm{~kg}$ the uncertainty of the volume is smaller in the double weighing than in the hydrostatic weighing; above $1 \mathrm{~kg}$ the reverse is true.

The relative measurement uncertainty of the volume depends on the nominal mass as well (Figure 2). For the double weighing method the correlation between the relative measurement uncertainty and the nominal mass is negative below $1 \mathrm{~kg}(-0.60)$ and negative above $1 \mathrm{~kg}(-0.35)$. For the hydrostatic method the correlation is negative below $1 \mathrm{~kg}(-0.45)$ and negative above $1 \mathrm{~kg}(-0.31)$. Note that weights smaller than $1 \mathrm{~kg}$ were measured on VK1 whereas weights larger than $1 \mathrm{~kg}$ were measured on VK10, which explains the step in the relative measurement uncertainty above $1 \mathrm{~kg}$. 

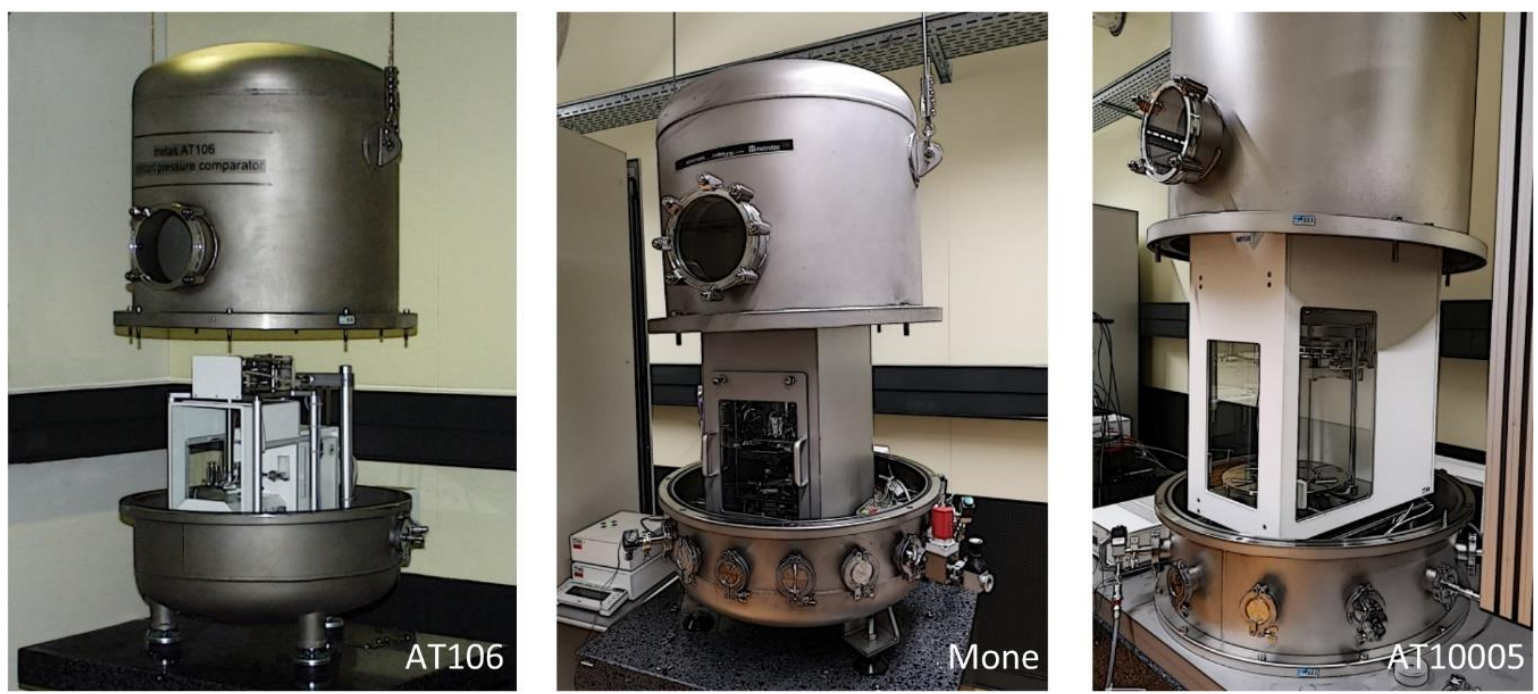

Figure 1: Mass comparators in air-tight enclosures in METAS

Table 3: Calculated volumes and expanded measurement uncertainties $(k=2)$ obtained from the double weighing and the hydrostatic weighing measurements

\begin{tabular}{|c|l|l|}
\hline \multirow{2}{*}{$\begin{array}{c}\text { Nominal } \\
\text { Mass }\end{array}$} & \multicolumn{2}{|c|}{ Volume / $\mathbf{c m}^{\mathbf{3}}$} \\
\cline { 2 - 3 } & \multicolumn{1}{|c|}{ Double weighing } & \multicolumn{1}{c|}{ Water } \\
\hline $10 \mathrm{~g}$ & $1.2488(3)$ & $1.2491(7)$ \\
\hline $20 \mathrm{~g}$ & $2.5005(4)$ & $2.5010(8)$ \\
\hline $20 \mathrm{~g} *$ & $2.5004(3)$ & $2.5004(2)$ \\
\hline $50 \mathrm{~g}$ & $6.2444(6)$ & $6.2450(6)$ \\
\hline $100 \mathrm{~g}$ & $12.4889(5)$ & $12.4903(8)$ \\
\hline $200 \mathrm{~g}$ & $24.9838(5)$ & $24.9833(6)$ \\
\hline $200 \mathrm{~g} *$ & $24.9835(6)$ & $24.9832(11)$ \\
\hline $500 \mathrm{~g}$ & $62.4473(11)$ & $62.4460(14)$ \\
\hline $1 \mathrm{~kg}$ & $124.8739(20)$ & $124.8739(20)$ \\
\hline $2 \mathrm{~kg}$ & $249.8089(207)$ & $249.8062(96)$ \\
\hline $2 \mathrm{~kg} *$ & $249.8389(417)$ & $249.8013(96)$ \\
\hline $5 \mathrm{~kg}$ & $624.2566(615)$ & $624.2107(106)$ \\
\hline
\end{tabular}

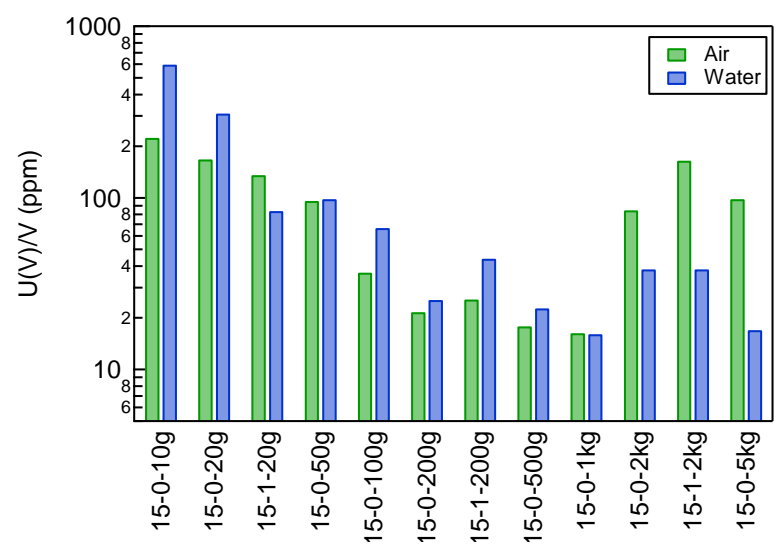

Figure 2: Expanded relative uncertainty of the volume of the weights obtained from double weighing and hydrostatic weighing measurements

For the hydrostatic weighing, the true (or conventional) mass of a weight is required to calculate the weight's volume. Therefore, we had determined the mass of each weight on our comparators beforehand in a direct comparison to a reference weight. The results of the true mass deviation from the nominal mass value are summarised in Table 4. Additionally, in order to check the goodness of the equation matrices at the two pressures, the true mass deviations from the nominal mass values have also been calculated, from the first $(950 \mathrm{hPa})$ and from the second $(750 \mathrm{hPa})$ double weighing measurements and are shown in Table 4 as well. The expanded measurement uncertainties are given in brackets and were calculated by using equation (15) on the basis of a Monte Carlo simulation. All measurement uncertainties refer to the uncertainty of mass and volume of the $1 \mathrm{~kg}$ reference weight $(15-0-1 \mathrm{~kg})$, which were $U(m)=17 \mu \mathrm{g}(k=2)$ and $U(V)=2 \mathrm{~mm}^{3}$ $(k=2)$. Note that these uncertainties were established before the introduction of the new definition of the kilogram.

Table 4: Calculated true mass deviations from nominal mass values and expanded measurement uncertainties $(k=2)$ obtained from the $1^{\text {st }}$ and $2^{\text {nd }}$ double weighing (DbW) and from the hydrostatic weighing

\begin{tabular}{|c|l|l|l|}
\hline $\begin{array}{c}\text { Nominal } \\
\text { Mass }\end{array}$ & \multicolumn{3}{|c|}{ Mass deviation from nominal mass } \\
\hline & $1^{\text {st }}$ DbW & \multicolumn{1}{|c|}{$\mathbf{2}^{\text {nd }} \mathbf{D b W}$} & \multicolumn{1}{c|}{$\begin{array}{c}\text { previous } \\
\text { hydrostatic } \\
\text { weighing }\end{array}$} \\
\hline $10 \mathrm{~g}$ & $0.015(1)$ & $0.015(1)$ & $0.014(3)$ \\
\hline $20 \mathrm{~g}$ & $0.016(1)$ & $0.016(1)$ & $0.004(3)$ \\
\hline $20 \mathrm{~g} *$ & $0.040(1)$ & $0.040(1)$ & $0.032(2)$ \\
\hline $50 \mathrm{~g}$ & $0.011(1)$ & $0.011(1)$ & $-0.004(4)$ \\
\hline $100 \mathrm{~g}$ & $0.052(2)$ & $0.052(2)$ & $0.031(2)$ \\
\hline $200 \mathrm{~g}$ & $0.072(3)$ & $0.072(3)$ & $0.049(12)$ \\
\hline $200 \mathrm{~g} *$ & $0.040(4)$ & $0.040(3)$ & $0.023(12)$ \\
\hline $500 \mathrm{~g}$ & $0.088(9)$ & $0.088(9)$ & $0.045(38)$ \\
\hline $1 \mathrm{~kg}$ & $0.117(17)$ & $0.117(17)$ & $0.048(13)$ \\
\hline $2 \mathrm{~kg}$ & $0.591(43)$ & $0.587(42)$ & $0.435(600)$ \\
\hline $2 \mathrm{~kg} *$ & $-0.145(58)$ & $-0.148(57)$ & $-0.340(600)$ \\
\hline $5 \mathrm{~kg}$ & $1.960(110)$ & $1.952(108)$ & $1.568(1500)$ \\
\hline & & & \\
\hline
\end{tabular}


On the basis of the Monte Carlo simulation we analysed the correlation between the estimated values of the mass and the volume. For this reason, we calculated the standardised form (z-score), $Z=(X-\mu) / \sigma$, of the simulated values, $X$, of the mass and the volume, respectively.

$$
\begin{aligned}
& Z_{\text {mass }, j}(p)=\frac{m_{j}(p)-\bar{m}_{j}}{s_{m, j}} \\
& Z_{\text {volume }, j}(p)=\frac{V_{j}(p)-\bar{V}_{j}}{s_{V, j}}
\end{aligned}
$$

Figure 3 shows the standardised variables of the mass and the volume calculated by a Monte Carlo simulation for the weights from $10 \mathrm{~g}$ to $5 \mathrm{~kg}$. We observed that the correlation between the estimated values for mass and volume depends on the nominal mass of the weight. Hence, we calculated the correlation coefficient

$$
\operatorname{Cor}(x, y)=\frac{\sum(x-\bar{x})(y-\bar{y})}{\sqrt{\sum(x-\bar{x})^{2}(y-\bar{y})^{2}}}
$$

between $Z_{\text {mass }, j}$ and $Z_{\text {volume }, j}$. The correlation coefficient is the smallest for the $1 \mathrm{~kg}$ weight and increases as the nominal mass decreases. Above $1 \mathrm{~kg}$, the correlation coefficient is significantly larger and seems to be independent of the nominal mass (Table $5)$.

Table 5: Correlation between the error on mass and density for the different values of mass

\begin{tabular}{|c|c|c|c|}
\hline $\begin{array}{c}\text { Nominal } \\
\text { Mass }\end{array}$ & Cor $(\boldsymbol{x}, \boldsymbol{y})$ & $\begin{array}{c}\text { Nominal } \\
\text { Mass }\end{array}$ & $\operatorname{Cor}(\boldsymbol{x}, \boldsymbol{y})$ \\
\hline $10 \mathrm{~g}$ & 0.83 & $200 \mathrm{~g}^{*}$ & 0.07 \\
\hline $20 \mathrm{~g}$ & 0.74 & $500 \mathrm{~g}$ & 0.01 \\
\hline $20 \mathrm{~g}^{*}$ & 0.66 & $1 \mathrm{~kg}$ & 0.00 \\
\hline $50 \mathrm{~g}$ & 0.52 & $2 \mathrm{~kg}$ & 0.54 \\
\hline $100 \mathrm{~g}$ & 0.09 & $2 \mathrm{~kg} *$ & 0.78 \\
\hline $200 \mathrm{~g}$ & 0.04 & $5 \mathrm{~kg}$ & 0.58 \\
\hline
\end{tabular}

To compare the calculated volumes from the double weighing and from the hydrostatic weighing measurements with each other, we calculated the degree of equivalence (DoE) according to Cox [7]. The DoE is in good agreement between the two methods in the range from $10 \mathrm{~g}$ to $5 \mathrm{~kg}$, except for the $100 \mathrm{~g}$ weight (Figure 4).
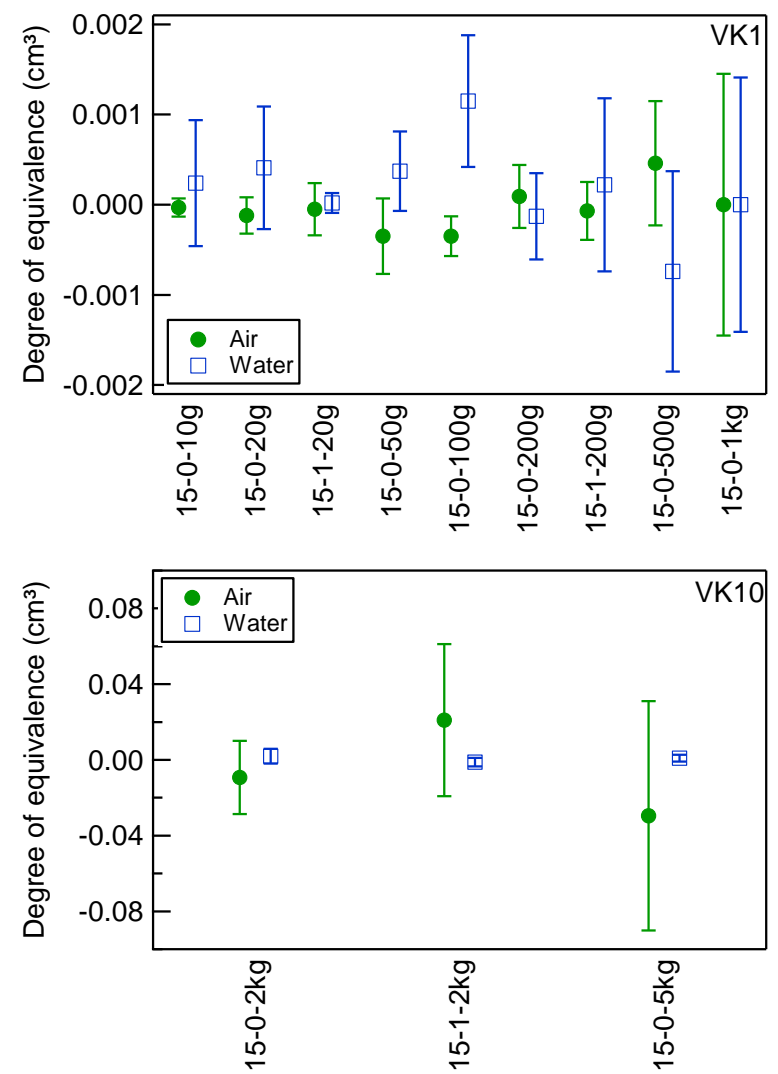

Figure 4: Degree of equivalence of the calculated volumes of the weights between the two measurement methods double weighing and hydrostatic weighing. Error bars represent expanded uncertainty $k=2$. Top: $10 \mathrm{~g}$ to $1 \mathrm{~kg}$ on VK1; Bottom: $2 \mathrm{~kg}$ to $5 \mathrm{~kg}$ on VK10

\section{DISCUSSION}

The double weighing method offers several advantages over hydrostatic weighing: the maintenance is less complex, it is less time consuming and is easier to perform the measurements,
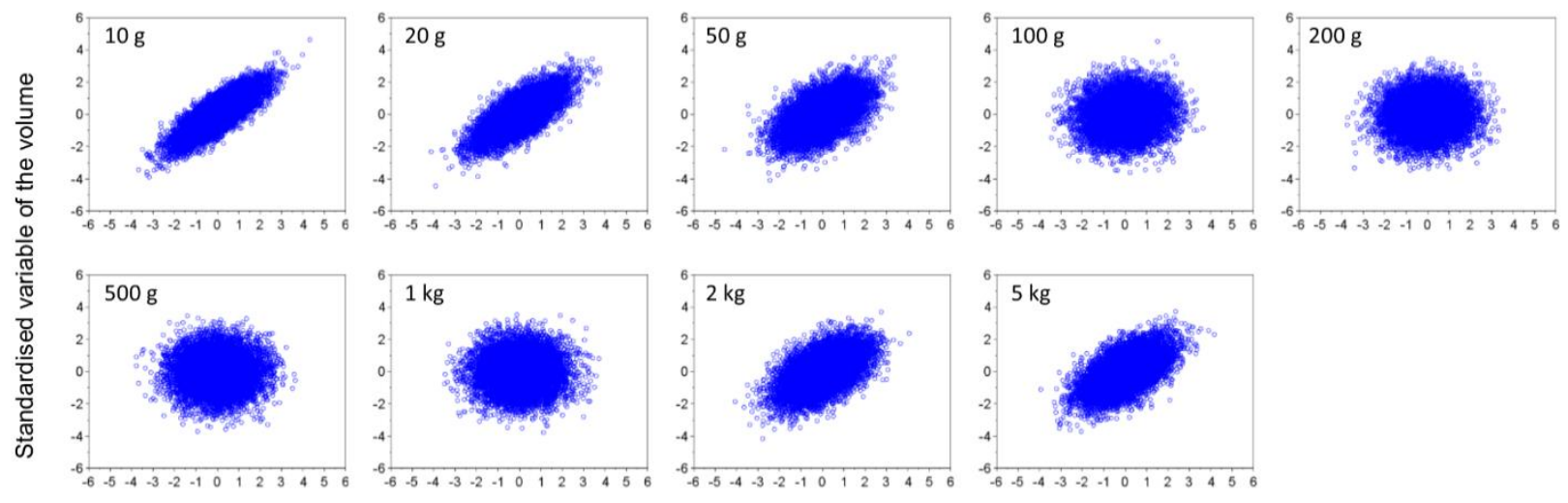

Standardised variable of the mass

Figure 3: Standardised variables of the calculated values for the mass and the volume of the test weights. The values come from a Monte-Carlo simulation with $N=10000$ iterations 
the calculations are simpler, and it does not contaminate the surface of the weights. The achieved measurement uncertainties are similar to those of the hydrostatic weighing, and even better for small weights. The discrepancy in the calculated volume of the $100 \mathrm{~g}$ weight between the double weighing and the hydrostatic weighing remains unclear but may be related to an error made at the time of hydrostatic weighing. The volume value obtained from the double weighing measurements was confirmed by repeating the double weighing measurements on the MonePlus comparator, which is similar to the Mone but can also be used in vacuum. The difference between the two measured volumes for the $100 \mathrm{~g}$ weight was only $10 \mathrm{ppm}$ and was thus well within the measurement uncertainty (not shown in Figure 4).

The pairs of weights with the same nominal mass, i.e. $20 \mathrm{~g}, 200 \mathrm{~g}$ and $2 \mathrm{~kg}$, do not have the same measurement uncertainties on their respective volumes. The reason for this is the following: the dispersion of the measured weighing values in the hydrostatic weighing of $15-0-20 \mathrm{~g}$ and $15-1-200 \mathrm{~g}$ is larger than the dispersion of the measured weighing values of their counterparts 15-1-20g and 15-0-200g, respectively. The difference between the volume uncertainties of $15-0-2 \mathrm{~kg}$ and $15-1-2 \mathrm{~kg}$ in the double weighing measurements is more difficult to find out because these uncertainties originate from a closed series of measurements (group weighing).

On the basis of the minimum and maximum limits for density of class $E_{1}$ weights [8], we calculated the equivalent values for volume (Table 6).

Table 6: Minimum and maximum limits for density and volume of class $\mathrm{E}_{1}$ weights according to OIML R 111-1

\begin{tabular}{|c|c|c|c|c|}
\hline $\begin{array}{c}\text { Nominal } \\
\text { Mass }\end{array}$ & \multicolumn{2}{|c|}{$\begin{array}{l}\text { Density } \\
/ \mathrm{kg} \cdot \mathbf{m}^{-3}\end{array}$} & \multicolumn{2}{|c|}{$\begin{array}{c}\text { Volume } \\
/ / \mathrm{cm}^{3} \\
\end{array}$} \\
\hline & $\min$ & $\max$ & $\min$ & $\max$ \\
\hline $10 \mathrm{~g}$ & 7740 & 8280 & 1.208 & 1.292 \\
\hline $20 \mathrm{~g}$ & 7840 & 8170 & 2.448 & 2.551 \\
\hline $20 \mathrm{~g} *$ & 7840 & 8170 & 2.448 & 2.551 \\
\hline $50 \mathrm{~g}$ & 7920 & 8080 & 6.188 & 6.313 \\
\hline $100 \mathrm{~g}$ & \multirow{8}{*}{7934} & \multirow{8}{*}{8067} & 12.396 & 12.604 \\
\hline $200 \mathrm{~g}$ & & & 24.792 & 25.208 \\
\hline $200 \mathrm{~g} *$ & & & 24.792 & 25.208 \\
\hline $500 \mathrm{~g}$ & & & 61.981 & 63.020 \\
\hline $1 \mathrm{~kg}$ & & & 123.962 & 126.040 \\
\hline $2 \mathrm{~kg}$ & & & 247.924 & 252.080 \\
\hline $2 \mathrm{~kg} *$ & & & 247.924 & 252.080 \\
\hline $5 \mathrm{~kg}$ & & & 619.809 & 630.199 \\
\hline
\end{tabular}

The results in Table 3 show that the volumes of our weights, determined by double weighing and hydrostatic weighing, are all within the minimum and maximum limits given by OIML R 111-1.

\section{SUMMARY}

We are able to achieve the full dissemination of multiples and submultiples of a set of weights by using group weighings in two different air densities. The measurements are traceable to the mass and to the volume of the reference weight. The technique is promising as there is no contamination from a liquid, and it enables measuring the full range of mass values covered by the constant air density comparators of a laboratory. This technique is well suited for the dissemination of the mass and the volume based on the new definition of the kilogram using a silicon sphere whose mass and volume are known with high precision.

\section{REFERENCES}

[1] M. T. Clarkson, R. S. Davis, C. M. Sutton, J. Coarasa, "Determination of volumes of mass standards by weighings in air", Metrologia, vol. 38 , no. 1, pp. 1724, 2001.

[2] A. Malengo, W. Bich, "Simultaneous determination of mass and volume of a standard by weighings in air", Metrologia, vol. 49, no. 3, pp. 289-293, 2012.

[3] K. H. Chang, Y. J. Lee, "Hydrostatic weighing at KRISS”, Metrologia, vol. 41, no. 2, pp. S95-S99, March 2004.

[4] M. Kochsiek, M. Gläser, Massebestimmung. VCH Verlagsgesellschaft mbH, ISBN 3-527-29352-3, 1997.

[5] K. Marti, "Dissemination of the kilogram at METAS: Extended Method of Lagrange Multipliers for Air Buoyancy Correction", in Proc. of IMEKO 23rd TC3 Int. Conf., Helsinki, Finland, 2017.

[6] Y. Su, K. Marti, Ch. Wuethrich, "The determination of the volume of weights in the range of $1 \mathrm{~g}-5 \mathrm{~kg}$ : a comparison of hydrostatic weighing and double weighing in air using the Monte Carlo Simulation" ACTA IMEKO vol. 9, no. 1, pp. 61-68, March 2020.

[7] M. G. Cox, "The evaluation of key comparison data", Metrologia, vol. 39, pp. 589-595, 2002.

[8] OIML R 111-1, "Weights of classes $E_{1}, E_{2}, F_{1}, F_{2}, M_{1}$, $\mathrm{M}_{1-2}, \mathrm{M}_{2}, \mathrm{M}_{2-3}$ and $\mathrm{M}_{3}$ - Part 1: Metrological and technical requirements", OIML TC 9/SC 3, 2004. 